\title{
Reduced-Capacity Inrush Current Suppressor Using a Matrix Converter in a Wind Power Generation System with Squirrel-Cage Induction Machines
}

\author{
Sho Shibata ${ }^{1,+}$, Hiroaki Yamada ${ }^{1, *}$, Toshihiko Tanaka ${ }^{1, \dagger}$ and Masayuki Okamoto ${ }^{2,+}$ \\ 1 Graduate School of Science and Engineering, Yamaguchi University, 2-16-1 Tokiwadai, Ube, \\ Yamaguchi 755-8611, Japan; v019vk@yamaguchi-u.ac.jp (S.S.); totanaka@yamaguchi-u.ac.jp (T.T.) \\ 2 Department of Electrical Engineering, National Institute of Technology, Ube College, 2-14-1 Tokiwadai, \\ Ube, Yamaguchi 755-8555, Japan; mokamoto@ube-k.ac.jp \\ * Correspondence: hiro-ymd@yamaguchi-u.ac.jp; Tel.: +81-836-85-9471; Fax: +81-836-85-9472 \\ + These authors contributed equally to this work.
}

Academic Editor: Jang-Ho Lee

Received: 29 December 2015; Accepted: 14 March 2016; Published: 21 March 2016

\begin{abstract}
This paper describes the reduced capacity of the inrush current suppressor using a matrix converter (MC) in a large-capacity wind power generation system (WPGS) with two squirrel-cage induction machines (SCIMs). These SCIMs are switched over depending on the wind speed. The input side of the MC is connected to the source in parallel. The output side of the MC is connected in series with the SCIM through matching transformers. The modulation method of the $\mathrm{MC}$ used is direct duty ratio pulse width modulation. The reference output voltage of the $\mathrm{MC}$ is decided by multiplying the SCIM current with the variable control gain. Therefore, the MC performs as resistors for the inrush current. Digital computer simulation is implemented to confirm the validity and practicability of the proposed inrush current suppressor using PSCAD/EMTDC (power system computer-aided design/electromagnetic transients including DC). Furthermore, the equivalent resistance of the $\mathrm{MC}$ is decided by the relationship between the equivalent resistance and the capacity of the MC. Simulation results demonstrate that the proposed inrush current suppressor can suppress the inrush current perfectly.
\end{abstract}

Keywords: wind power generation; matrix converter; inrush current; voltage sag

\section{Introduction}

The demand for energy in the world continues to increase. Renewable energy is very important for solving the demand for energy. The wind power capacity in the world has reached 369,597 MW [1]. Squirrel-cage induction machines (SCIMs) are widely used because of their reliability and low cost. In large-capacity wind power generation systems (WPGS), two generators are switched over depending on the wind speed. SCIM has an inrush current of about six-times the rated current at the start-up condition, because it does not have an excitation source [2]. This inrush current causes the voltage sag in the power system. Normally, a soft-starter, which consists of reverse-parallel connected thyristors, is used to limit the inrush current in WPGS [3]. However, a soft-starter generates harmonic currents with the switching of thyristors. A method for compensating harmonic currents using a shunt active filter has been proposed for avoiding the harmonic currents caused by the soft-starter [4]. In this method, a pulse width modulation (PWM) converter, which performs as the shunt active filter, compensates both the harmonic currents and fundamental reactive power. However, a large-capacity PWM converter, with a rating as high as 70\% of the SCIM rating of the wind turbine, is necessary, because the PWM converter directly supplies the fundamental reactive power generated by the SCIM in both the steady state and transient state. In [5], a compensating method for harmonic currents using 
a hybrid active power filter has been proposed. This method can compensate the harmonic current with a small-capacity hybrid active filter. However, the calculation is complex, and the control range of power factor is narrow because of fixed phase-leading capacity. In [6], a method of connecting resistors in series with the induction machine has been proposed. This method can suppress the inrush current by simple composition without harmonic currents. However, the series-connected resistors have large energy losses in the inrush current suppression.

We have proposed the inrush current suppressor in WPGS with a 2.2-kW SCIM by using a matrix converter (MC) [7]. The input side of the MC is connected in parallel to the power system. The output side of the MC is connected in series with the induction machine through matching transformers. Many modulation methods of MC have been proposed [8-13]. In [7], the virtual AC/DC/AC modulation method was used. In [9], the virtual AC/DC/AC modulation method treats an $\mathrm{MC}$ as an $\mathrm{AC} / \mathrm{DC} / \mathrm{AC}$ circuit consisting of a rectifier and an inverter. The direct $\mathrm{AC}$ modulation method has a high degree of freedom of control patterns, which is an advantage that can be applied to various control methods, but the control method is complex. The output voltage of the MC is decided by multiplying the control gain and SCIM current. This means that the output side of the MC performs as the resistor. In [7], the proposed inrush current suppressor can suppress the inrush current. However, the THD (total harmonic distortion) was high because of the switching ripple current of the MC. In [14], the direct duty ratio pulse width modulation (DDRPWM) method [13] is used for the proposed inrush current suppressor. The DDRPWM method decides the duty ratio by simple equations. This method can perform easy switching control among the direct AC modulation methods. The switching ripple of the input current of the $\mathrm{MC}$ is low because all input phases are used in one switching cycle. In [14], the proposed inrush current suppressor has suppressed the inrush current with low THD. On the other hand, the capacity of the proposed inrush current suppressor must be considered for practical use in large-capacity WPGS with two SCIMs.

This paper describes the reduced capacity of the inrush current suppressor by using an MC in a large-capacity WPGS with two SCIMs. Two SCIMs, which used 100 and $400 \mathrm{~kW}$, are switched over depending on the wind speed in this paper. The capacity of the inrush current suppressor depends on the equivalent resistance of the output side of the MC. In this paper, the optimal equivalent resistance is decided by the simulation results. At first, the inrush current is confirmed by using the power system transient analysis simulator PSCAD/EMTDC (power system computer-aided design/electromagnetic transients including DC). After that, the technical issues of the conventional inrush current suppressors are described in detail. Then, the validity of the proposed inrush current suppressor using MC is revealed. Furthermore, the most appropriate resistance of the MC is decided for reducing the capacity of the MC.

\section{Inrush Current Suppressor Using MC}

Figure 1 shows the system configuration with the previously-proposed inrush current suppressor using MC [14] in a large-capacity WPGS. Two SCIMs, which used 100 and $400 \mathrm{~kW}$ in this paper, are switched over depending on the wind speed. The cut-in wind speed is $3 \mathrm{~m} / \mathrm{s}$, and the cut-out wind speed is $25 \mathrm{~m} / \mathrm{s}$ in a general large-capacity WPGS. The 100-kW SCIM is connected to the power system when the wind speed is from 3 to $8 \mathrm{~m} / \mathrm{s}$, and the $400 \mathrm{~kW} \mathrm{SCIM}$ is connected to the power system when the wind speed is from 8.0001 to $25 \mathrm{~m} / \mathrm{s}$. The input side of the MC is connected in parallel to the power system. The output side of the MC is connected in series with the SCIM through matching transformers. Both the input and output sides of the MC are connected to a low-pass filter for reducing the switching ripple. The clamp circuit is connected to prevent voltage spikes [15]. 


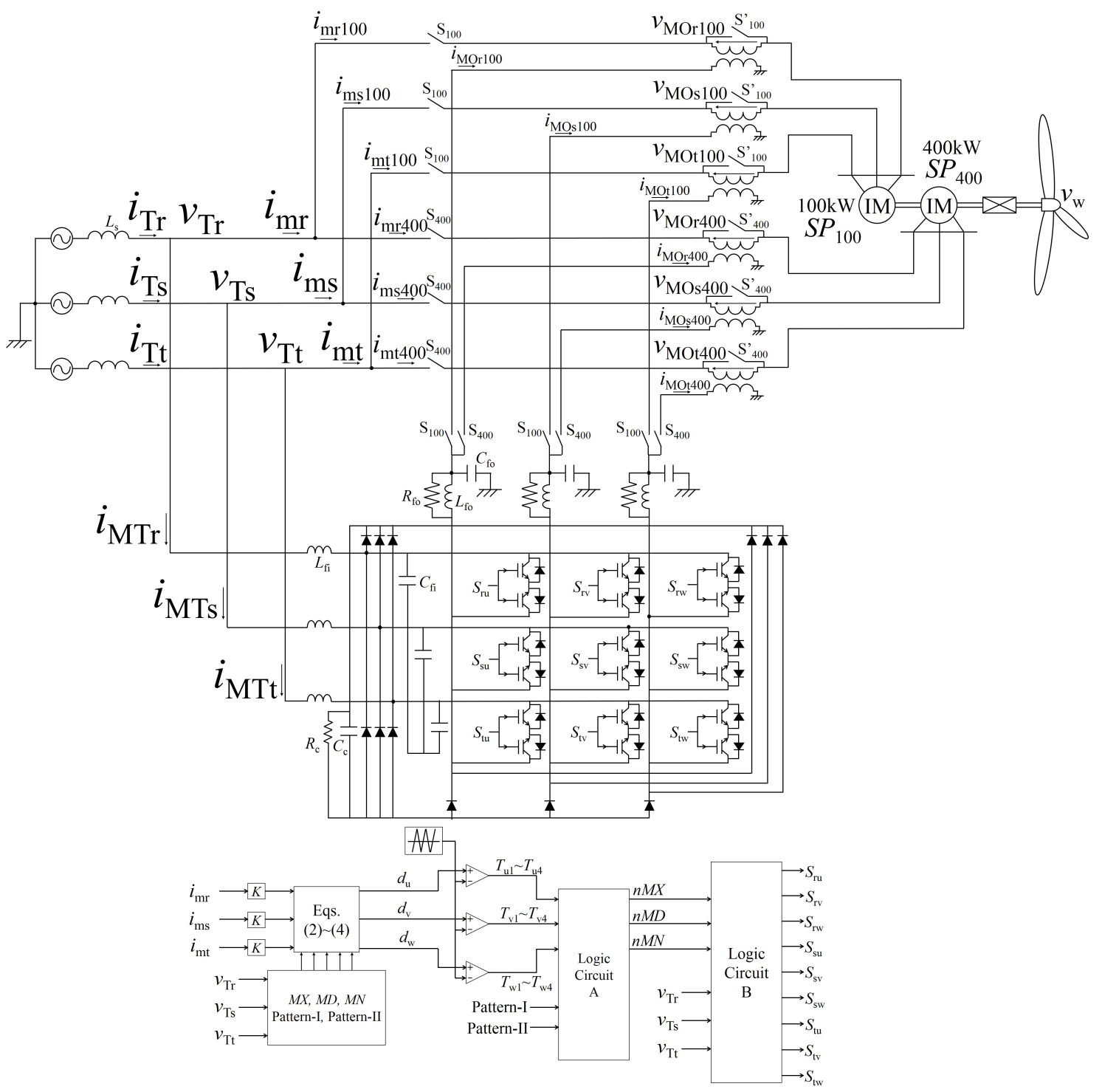

Figure 1. System configuration with the proposed inrush current suppressor using matrix converter (MC) in a large-capacity wind power generation system (WPGS).

The reference output voltage of the MC is decided as follows:

$$
v_{\mathrm{o} n}^{*}=K \cdot i_{\mathrm{m} n} \quad(n=\mathrm{r}, \mathrm{s}, \mathrm{t})
$$

where $K$ is the control gain and $n$ indicates the output phase of $r$, $s$ and $t$. The output voltage of the MC and SCIM current are in phase. Thereby, the output side of the MC performs as resistors of $K[\Omega]$. $K$ is decreased to zero after inrush current suppression, and then, the MC is removed by the switches $\mathrm{S}^{\prime}{ }_{100}$ or $\mathrm{S}_{400}$.

In this paper, the modulation method of the MC is used DDRPWM. The output voltages can be directly synthesized by updating the duty ratio values at each switching cycle without complex calculation. The DDRPWM uses the line-to-line input voltages to synthesize the output voltages. The duty ratios have two equations for each input voltage. $M X, M D$ and $M N$ denote the maximum, medium and minimum input voltage of the MC, respectively. The switching pattern when $M X-M N>M D-M N$ is named Pattern I. The switching pattern when 
$M D-M N>M X-M D$ is named Pattern II. The duty ratios of each output phase are obtained by the following equations:

$$
\begin{aligned}
& d_{\mathrm{u}}=\left\{\begin{array}{l}
\frac{v_{\mathrm{ou}}^{*}-M X}{n \cdot M N-n \cdot M D+M D-M N} \text { for Pattern I } \\
\frac{v_{\mathrm{ou}}^{*}-(n \cdot M X-n \cdot M D+M D)}{M N-n \cdot M X-M D+n \cdot M D} \text { for Pattern II }
\end{array}\right. \\
& d_{\mathrm{v}}=\left\{\begin{array}{l}
\frac{v_{\mathrm{ov}}^{*}-M X}{n \cdot M N-n \cdot M D+M D-M N} \text { for Pattern I } \\
\frac{v_{\mathrm{ov}}^{*}-(n \cdot M X-n \cdot M D+M D)}{M N-n \cdot M X-M D+n \cdot M D} \text { for Pattern II }
\end{array}\right. \\
& d_{\mathrm{w}}=\left\{\begin{array}{l}
\frac{v_{\mathrm{ow}}^{*}-M X}{n \cdot M N-n \cdot M D+M D-M N} \text { for Pattern I } \\
\frac{v_{\mathrm{ow}}^{*}-(n \cdot M X-n \cdot M D+M D)}{M N-n \cdot M X-M D+n \cdot M D} \text { for Pattern II }
\end{array}\right.
\end{aligned}
$$

where $v_{\mathrm{o} n}^{*}$ is the reference output voltage of Equation (1). Figure 2 shows an example of the switching states between the duty ratio $d_{\mathrm{u}}$ of the output $\mathrm{u}$-phase and the input phase. The duty ratios are decided by comparing the duty ratio $d_{\mathrm{u}}$ and the carrier signal $v_{\text {tri }}$. In the case of Pattern I, when $d_{\mathrm{u}}$ is larger than $v_{\text {tri }}, \mathrm{MX}$ is connected. MN is connected when $d_{\mathrm{u}}$ is smaller than $v_{\text {tri }}$ in $T_{1}$. MD is connected when $d_{\mathrm{u}}$ is smaller than $v_{\text {tri }}$ in $T_{2}$. In the case of Pattern II, when $d_{\mathrm{u}}$ is smaller than $v_{\text {tri }}, M N$ is connected. $M X$ is connected when $d_{\mathrm{u}}$ is larger than $v_{\text {tri }}$ in $T_{1} . M D$ is connected when $d_{\mathrm{u}}$ is larger than $v_{\text {tri }}$ in $T_{2}$. $n$, which is used for input current synthesis, is defined as $T_{1} / T_{\mathrm{s}}$. The $T_{\mathrm{u} 1} \sim T_{\mathrm{u} 4}$ of Figure 2 are decided by comparison of the carrier signal and the duty ratio $d_{\mathrm{u}}$. Similarly, the $T_{\mathrm{v} 1} \sim T_{\mathrm{v} 4}, T_{\mathrm{w} 1} \sim T_{\mathrm{w} 4}$ are decided, as well. Logic Circuit A of Figure 1 chooses which $T_{\mathrm{u} 1} \sim T_{\mathrm{u} 4}$, $T_{\mathrm{v} 1} \sim T_{\mathrm{v} 4}$ and $T_{\mathrm{w} 1} \sim T_{\mathrm{w} 4}$ to connect $\mathrm{MX}, \mathrm{MD}$ and $\mathrm{MN}$ under the conditions of Patterns I and II. Logic Circuit $B$ of Figure 1 decides the timing that connects the input with output.
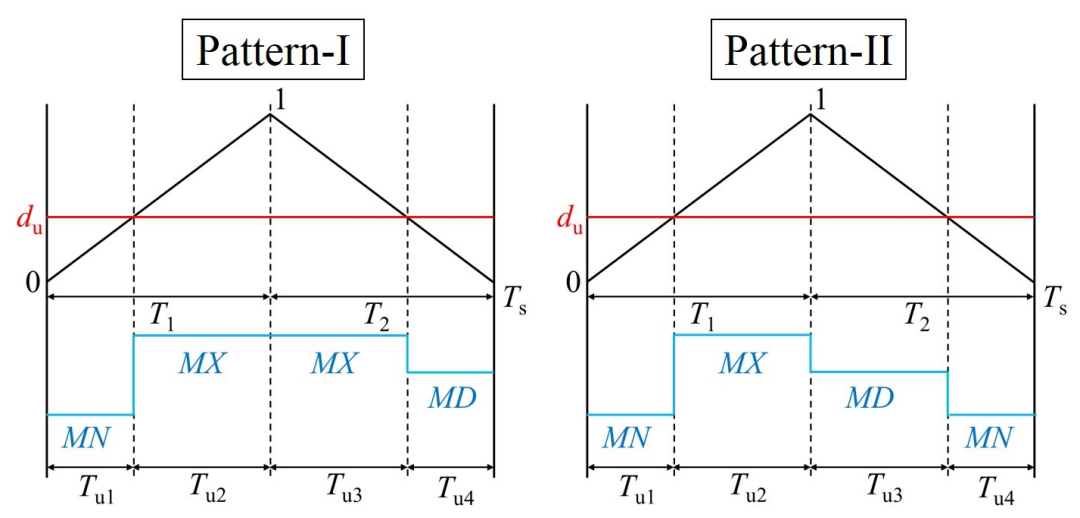

Figure 2. Switching states in Pattern I and Pattern II in the direct duty ratio pulse width modulation (DDRPWM) method.

\section{Simulation Results}

All simulations are carried out using PSCAD/EMTDC in order to verify the effectiveness of the proposed reduced-capacity inrush current suppressor. The technical issues of the conventional inrush current suppressors are described in detail. The validity of the proposed inrush current suppressor using the MC is revealed. Furthermore, the most appropriate resistance of the MC is decided for reducing the capacity of the MC. 
Table 1 shows the parameters of the SCIMs. In all simulations, the source side inductor $L_{\mathrm{s}}$ is $0.1 \mathrm{mH}$, which is about 5\% relative to the rated impedance of $400 \mathrm{~kW} \mathrm{SCIM}$. Figure 3 shows the simulation condition. The 100-kW SCIM is connected to the grid from 3 to $8 \mathrm{~m} / \mathrm{s}$. The 400-kW SCIM is connected to the grid over $8 \mathrm{~m} / \mathrm{s}$.

Table 1. Parameters of the squirrel-cage induction machines (SCIMs).

\begin{tabular}{ccc}
\hline Item & 100-kW SCIM & 400-kW SCIM \\
\hline Rated power (kW) & 100 & 400 \\
Rated phase voltage (V) & 277.13 & 277.13 \\
Rated phase current (A) & 120.28 & 481.12 \\
Rated frequency (Hz) & 50 & 50 \\
Number of pole & 6 & 4 \\
Synchronous speed (rpm) & 1000 & 1500 \\
Rated wind speed (m/s) & 8 & 15 \\
\hline
\end{tabular}

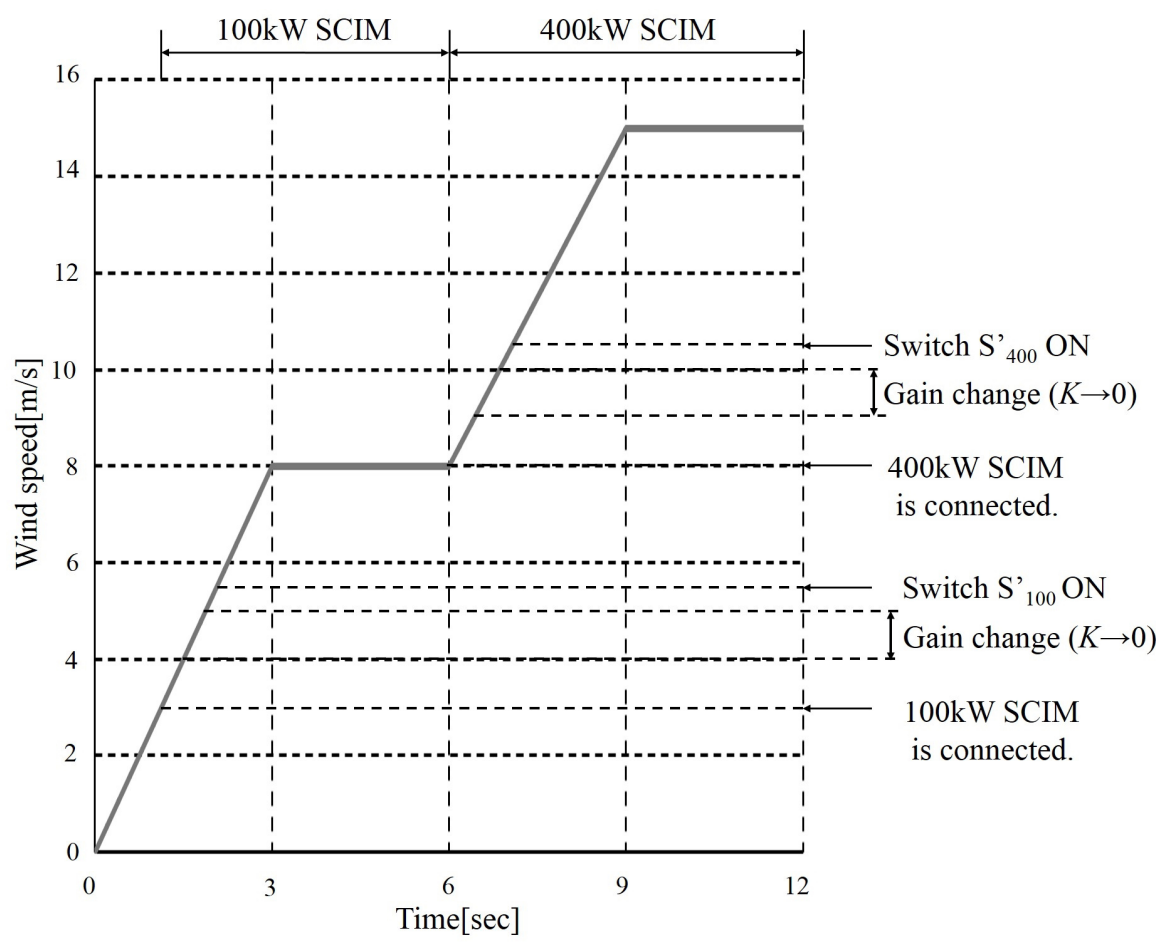

Figure 3. Simulation condition by the wind speed.

\subsection{Simulation Results of Direct Connection}

Digital computer simulation is implemented to confirm the inrush current and voltage sag when the SCIM is connected to the source directly. Figure 4 shows simulated waveforms for the $100-\mathrm{kW}$ SCIM. $v_{\mathrm{Tr}}$ is the r-phase receiving-end voltage; $i_{\mathrm{Tr}}$ is the source current; $S P_{100}$ is the rotating speed; and $v_{\mathrm{w}}$ is the wind speed. From Figure 4, the maximum value of the inrush current is $1145 \mathrm{~A}$. The voltage sag is about $6.89 \%$. Figure 5 shows simulated waveforms for the $400-\mathrm{kW} \mathrm{SCIM.} \mathrm{From} \mathrm{Figure} 5$, the maximum value of the inrush current is $3873 \mathrm{~A}$. The voltage sag is about $15.28 \%$. In general, a soft-starter is used to avoid the voltage sag caused by the inrush current. 


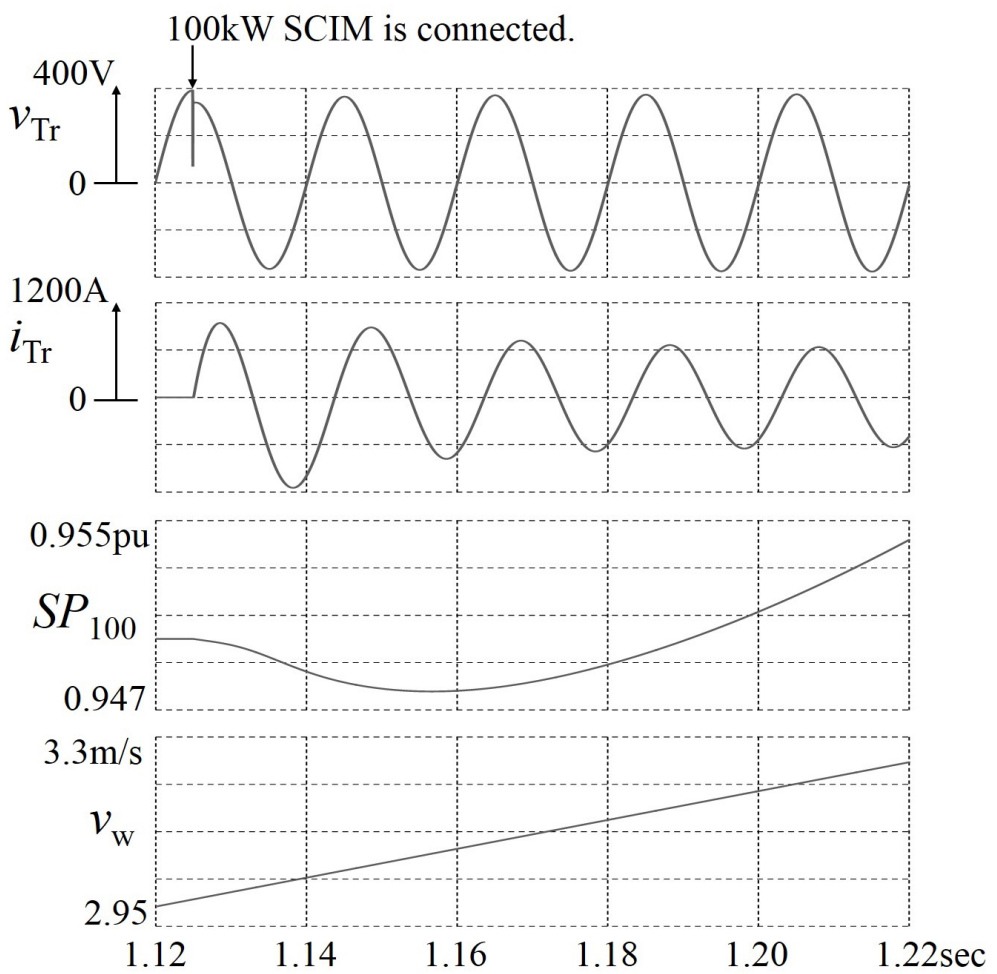

Figure 4. Simulated waveforms of the direct connection for the 100-kW SCIM.

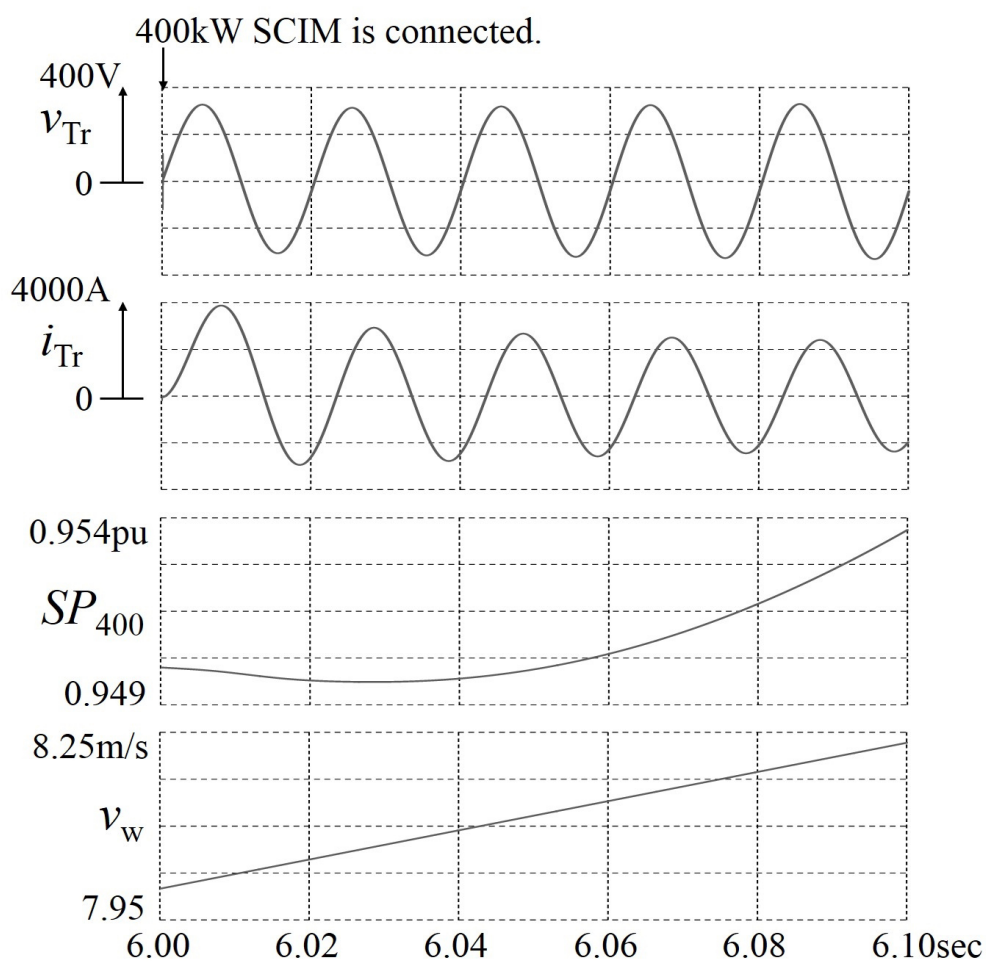

Figure 5. Simulated waveforms of the direct connection for the 400-kW SCIM.

\subsection{Conventional Inrush Current Suppressors}

The technical issues of the conventional inrush current suppressors are described in detail. Figure 6 shows the system configuration of the soft-starter in WPGS with two SCIMs. The soft-starter 
is widely used for large-capacity WPGS. The soft-starter consists of inverse-parallel-connected thyristors. The control angles of the thyristors are from $180^{\circ}$ to $0^{\circ}$ under the soft-starting condition. Therefore, the applied voltage of the SCIMs is gradually increased. Figure 7 shows the simulated waveforms with a soft-starter for the 100-kW SCIM. The soft-starter works for $2 \mathrm{~s}$ in this simulation. From this simulation result, the maximum source current is 649A. And then, the receiving-end voltage is decreased by $6.6 \%$ as compared to steady-state. Therefore, the soft-starter can suppress the inrush current. However, the source current includes harmonic current by the switching of the thyristors. Figure 8 shows the THD of the source current for the 100-kW SCIM in Figure 7. The THD of the source current changes during soft-starting. From Figure 8, the maximum value of the THD is $328.8 \%$. Figure 9 shows simulation waveforms of the source current for the $400-\mathrm{kW}$ SCIM of the soft-starter. The maximum source current is 1941A. And then, the receiving-end voltage is decreased by $13.8 \%$ as compared to steady-state. Figure 10 shows simulated waveforms with a soft-starter for the $400-\mathrm{kW}$ SCIM. From Figure 10, the maximum value of the THD is $329.6 \%$. Thus, the harmonic current compensation is necessary because of the harmonic current generation by the soft-starter.

Figure 11 shows the system configuration with the external resistors in [6]. The current is limited by the external resistor. The external resistors are shorted after suppressing the inrush current. Digital computer simulation is implemented to evaluate this external resistor method. $R_{100}$ and $R_{400}$ are 0.715 and $0.577 \Omega$, respectively. Figure 12 shows the simulation waveform of the source current for the 100-kW SCIM with external resistors. From this simulation result, no inrush current nor harmonic current occurs by using external resistors. Figure 13 shows the simulation waveform of the source current for the $400-\mathrm{kW}$ SCIM with external resistors. From this simulation result, no inrush current nor harmonic current occurs by using external resistors. However, large energy losses in series-connected external resistors occur during the start-up condition. The r-phase maximum losses are 119.0 and $212.6 \mathrm{~kW}$ for the $100-\mathrm{kW}$ and 400-kW SCIM, respectively. The large power losses are brought the increase of the volume of the external resistors.

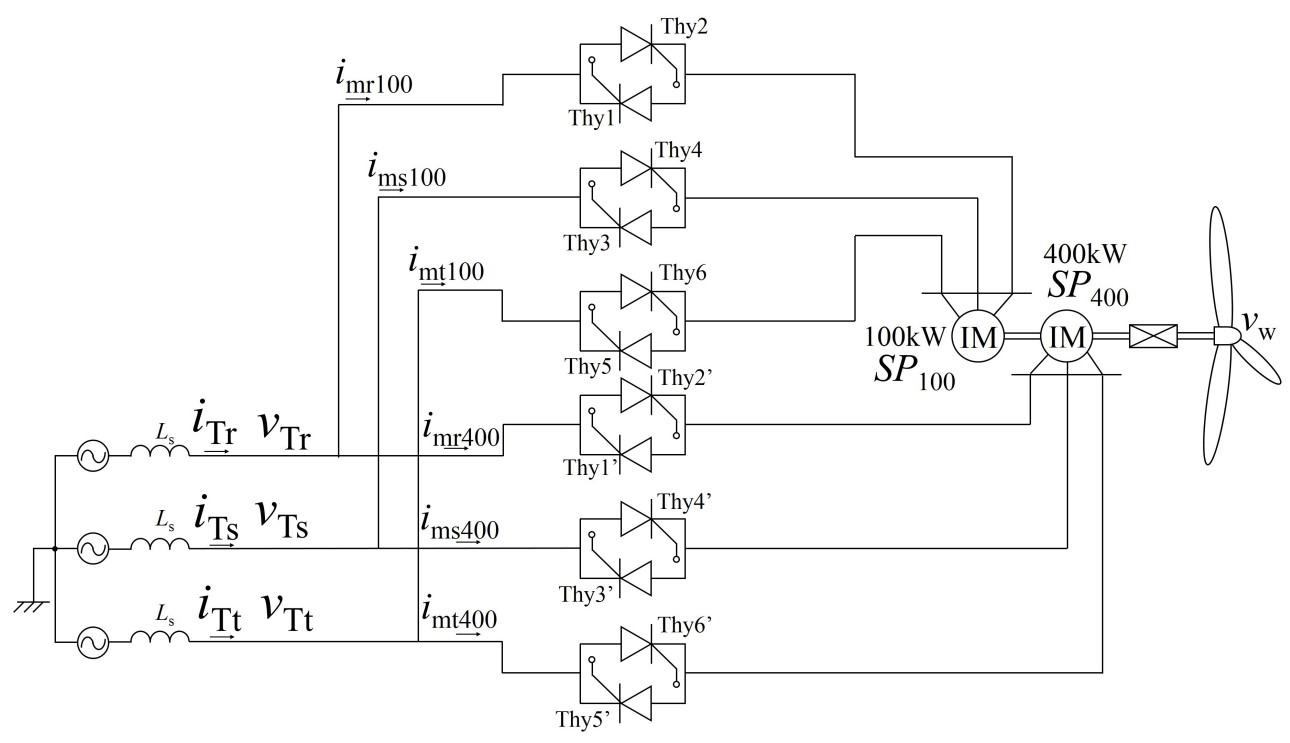

Figure 6. System configuration with the soft-starter in a large-capacity WPGS. 

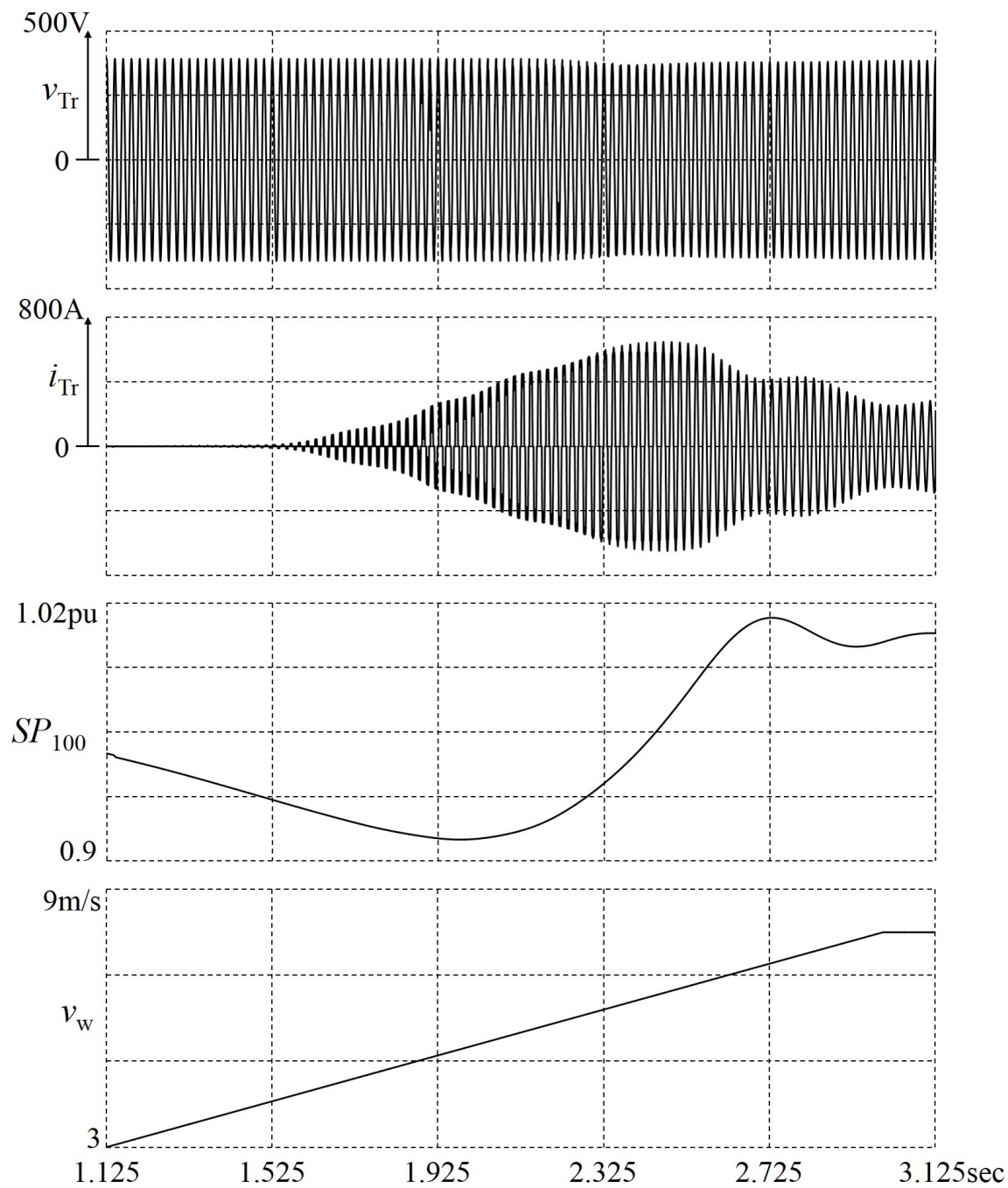

Figure 7. Simulated waveforms with a soft-starter for the 100-kW SCIM.

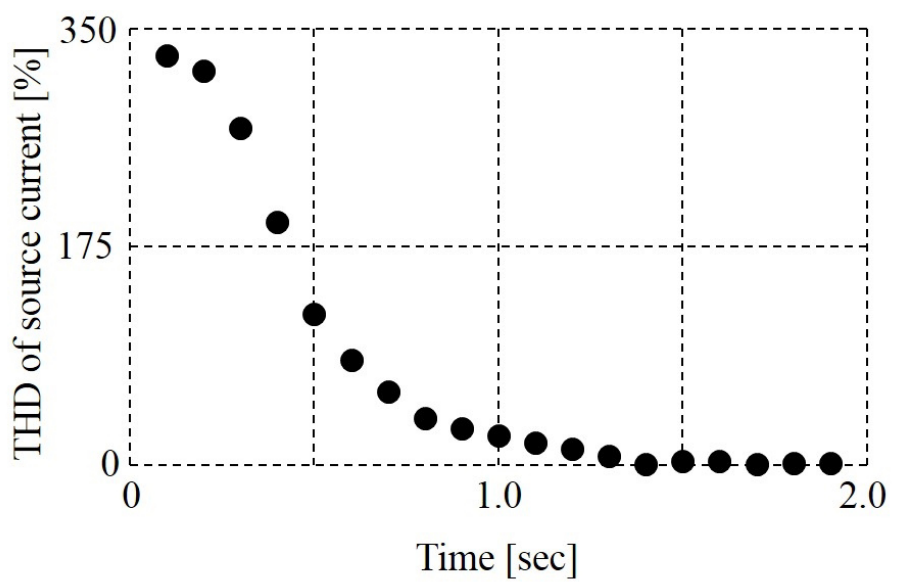

Figure 8. Source current total harmonic distortion (THD) of the soft-starter for the 100-kW SCIM in Figure 7. 

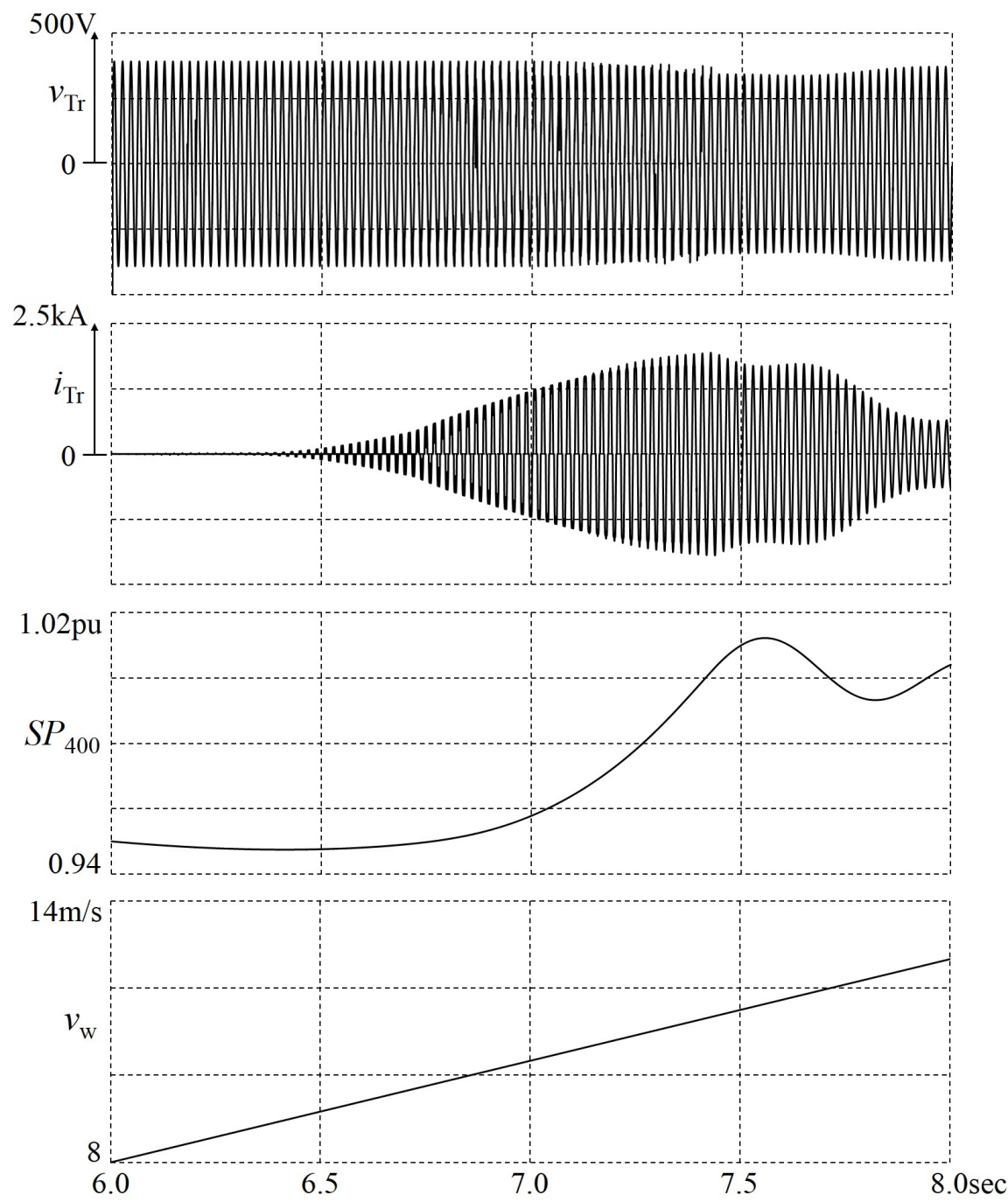

Figure 9. Simulated waveforms with a soft-starter for the 400-kW SCIM.

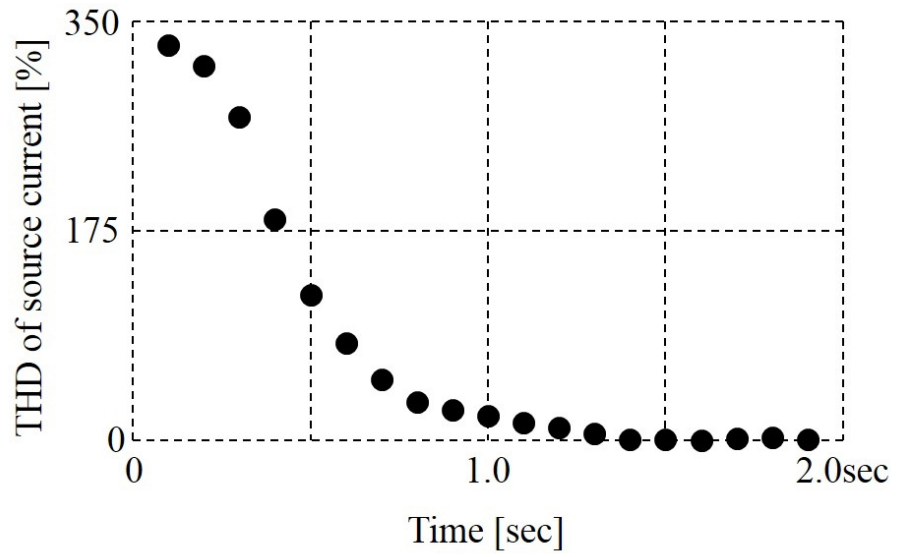

Figure 10. Source current THD of the soft-starter for the 400-kW SCIM in Figure 9. 


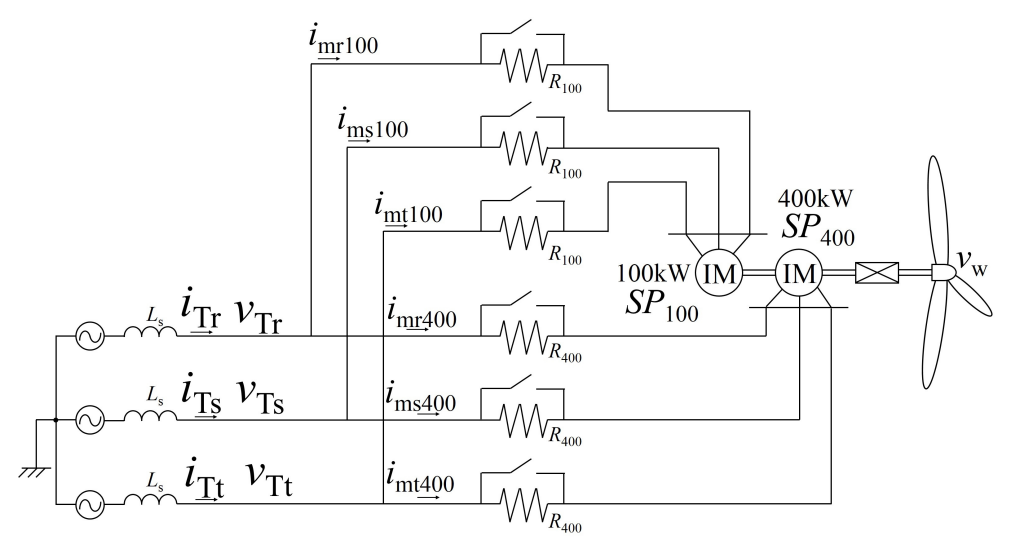

Figure 11. System configuration with external resistors.

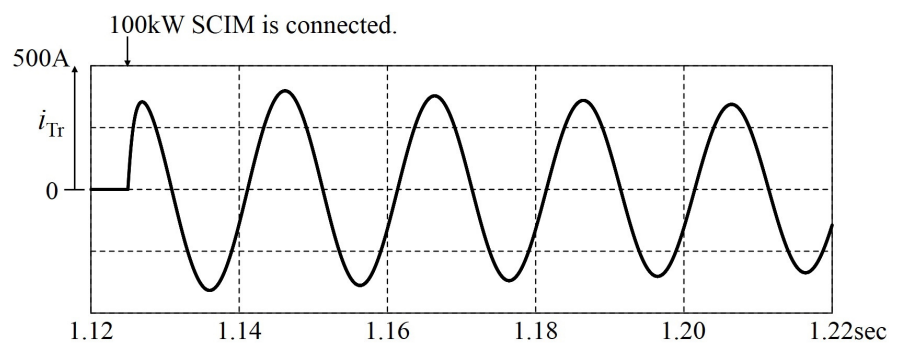

Figure 12. Source current for the 100-kW SCIM with the external resistors.

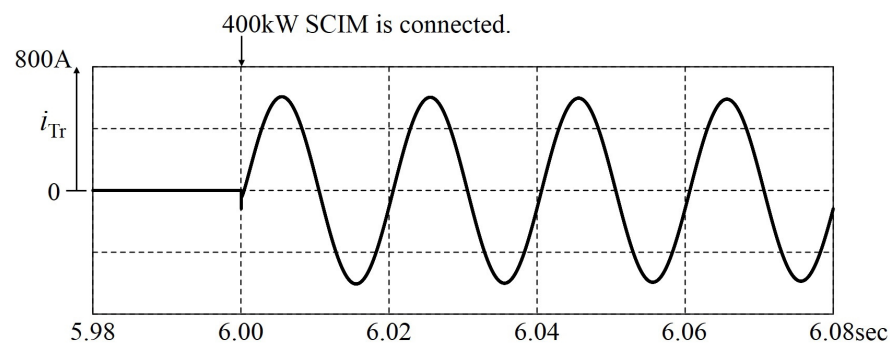

Figure 13. Source current for the 400-kW SCIM with the external resistors.

\subsection{Simulation Results with the Proposed Inrush Current Suppressor}

Digital computer simulation is implemented to confirm the validity of the proposed inrush current suppressor. Table 2 shows the circuit parameters in the simulation. The matching transformers are ideal transformers, and the turn ratio is 1:1. The initial value of the control gain $K$ is 0.3 . The equivalent resistance of the proposed inrush current suppressor is $0.715 \Omega$ when the $100-\mathrm{kW}$ SCIM is connected. The equivalent resistance of the inrush current suppressor is $0.577 \Omega$ when the 400-kW SCIM is connected. $K$ is decreased to zero after inrush current suppression.

Figure 14 shows simulation waveforms with the proposed inrush current suppressor for the $100-\mathrm{kW} \mathrm{SCIM.} v_{\operatorname{Tr}}$ is the r-phase receiving-end voltage; $i_{\operatorname{Tr}}$ is the source current; $i_{\mathrm{MTr}}$ is the r-phase input current of the MC; $i_{\text {MOr100 }}$ is the r-phase output voltage of the MC; $i_{\operatorname{mr} 100}$ is the r-phase SCIM current; $S P_{100}$ is the rotating speed; and $v_{\mathrm{w}}$ is the wind speed. From Figure 14, the output voltage of the MC and SCIM current is in phase. This means that the output side of the MC performs as the resistor in each phase. Therefore, the maximum SCIM current is $558 \mathrm{~A}$, and the voltage sag is about $1.5 \%$. The active power flows into the MC during the inrush current suppression. The active power is about $47.8 \mathrm{~kW}$. The receiving-end voltage $v_{\operatorname{Tr}}$ is opposite in phase to the input current $i_{\mathrm{MTr}}$ 
of the MC. The active power is regenerated to the grid. The regenerated power is about $33.6 \mathrm{~kW}$. In this simulation, the stationary losses of power devices and the resistors of the passive filters are included. From this simulation result, the inrush current of the 100-kW SCIM is reduced by about $50 \%$, and the voltage sag of the $100-\mathrm{kW} \mathrm{SCIM}$ is reduced by about $78 \%$ by connecting the proposed inrush current suppressor.

Table 2. Circuit constants.

\begin{tabular}{cc}
\hline Item & Value \\
\hline Source voltage $V_{\mathrm{s}}(\mathrm{V})$ & 480 \\
Source frequency $f(\mathrm{~Hz})$ & 50 \\
Source inductor $L_{\mathrm{s}}(\mathrm{mH})$ & 0.1 \\
Inductor of input filter $L_{\mathrm{fi}}(\mathrm{mH})$ & 1 \\
Capacitor of input filter $C_{\mathrm{fi}}(\mu \mathrm{F})$ & 25 \\
Inductor of output filter $L_{\mathrm{fo}}(\mathrm{mH})$ & 0.25 \\
Capacitor of output filter $C_{\mathrm{fo}}(\mu \mathrm{F})$ & 100 \\
Resistor of output filter $R_{\mathrm{fo}}(\Omega)$ & 1 \\
Resistor of clamp circuit $R_{\mathrm{c}}(\Omega)$ & 1000 \\
Capacitor of clamp circuit $C_{\mathrm{c}}(\mu \mathrm{F})$ & 500 \\
\hline
\end{tabular}

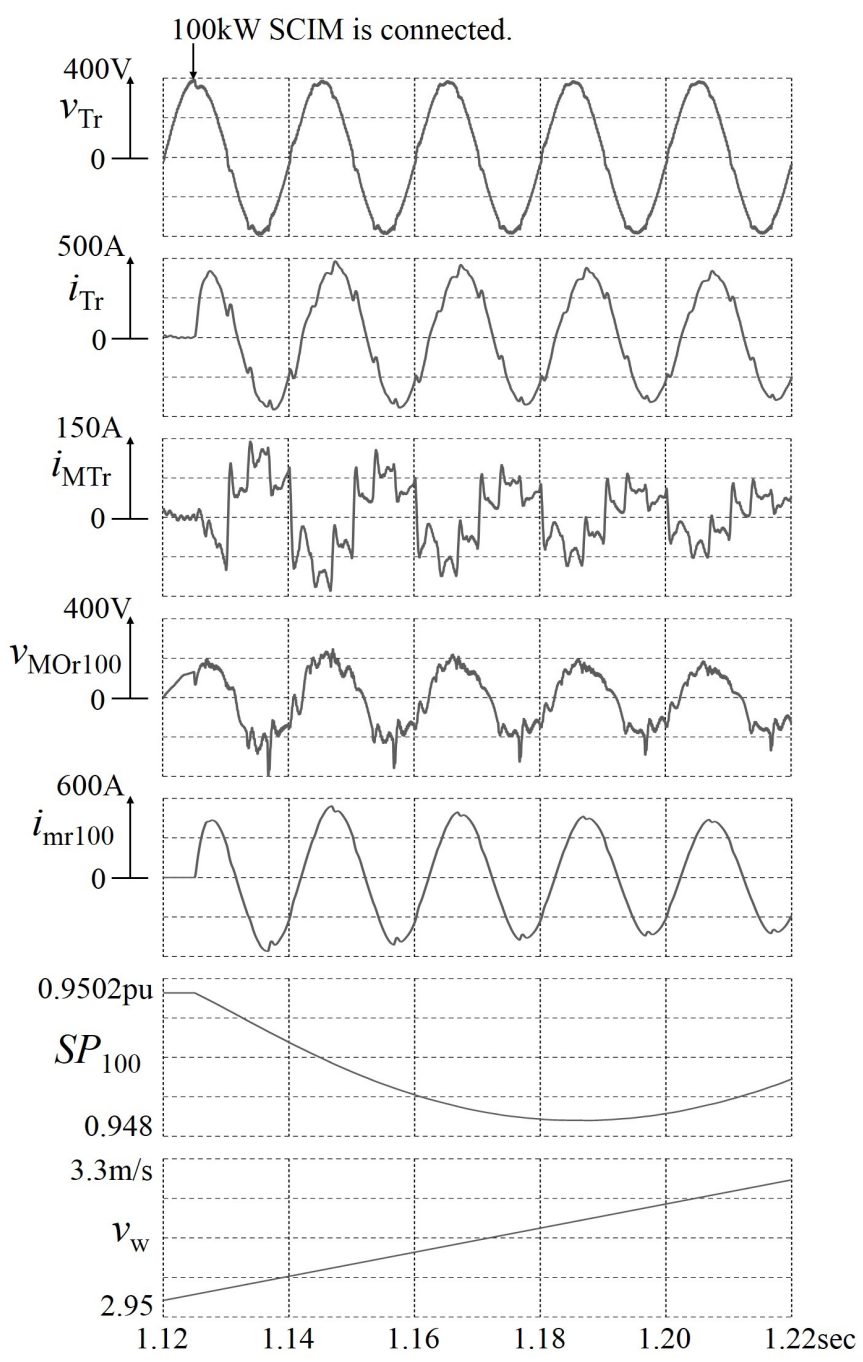

Figure 14. Simulation waveforms with the proposed inrush current suppressor for the 100-kW SCIM. 
Figure 15 shows the simulation waveforms with the proposed inrush current suppressor for the 400-kW SCIM. From Figure 15, the maximum SCIM current is $718 \mathrm{~A}$, and the voltage sag is about $0.76 \%$. The active power that flows into the $\mathrm{MC}$ is about $118.5 \mathrm{~kW}$. The receiving-end voltage $v_{\mathrm{Tr}}$ is also opposite in phase to the input current $i_{\mathrm{MTr}}$ of the MC. The regenerated power at the input side of the MC is about $79.8 \mathrm{~kW}$. From this simulation result, the inrush current of the $400-\mathrm{kW}$ SCIM is reduced by about $80 \%$, and the voltage sag of the $400 \mathrm{~kW}-\mathrm{SCIM}$ is reduced by about $95 \%$ by using the proposed inrush current suppressor. Thus, the validity of the proposed inrush current suppressor is confirmed by the simulation results.

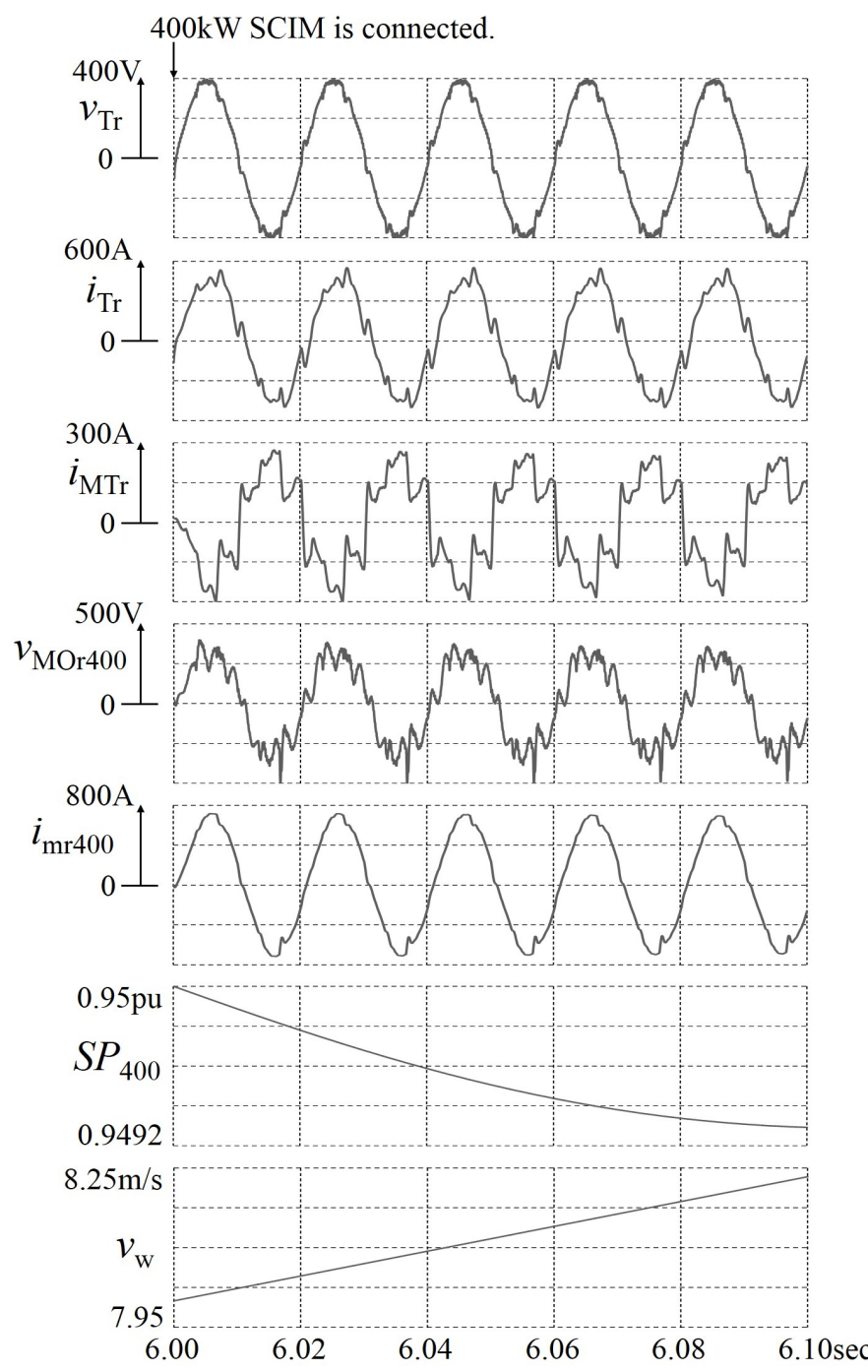

Figure 15. Simulation waveforms with the proposed inrush current suppressor for the 400-kW SCIM.

\subsection{Reduction of the Capacity for the Proposed Inrush Current Suppressor}

In the previous section, the basic validity was confirmed from the simulation results. However, the capacity of the proposed inrush current suppressor must be considered for practical use. In this section, the appropriate equivalent resistance of the output side of the proposed inrush current suppressor is decided for reducing the capacity of the proposed inrush current suppressor. The equivalent resistances are decided by the control gain $K$ and the turn ratio of the matching transformers. In this section, the control gain $K$ is set to the maximum duty ratio.

Figure 16a shows the relationship between the turn ratio and the proposed inrush current suppressor for the 100-kW SCIM. $R_{\mathrm{eq}}$ is the equivalent resistance of the output side of the proposed 
inrush current suppressor; $I_{\mathrm{mr} 100}$ is the r-phase maximum SCIM current; $U_{100}$ is the capacity of the proposed inrush current suppressor; and $R P_{100}$ is the ratio of the regenerated power through the MC. The horizontal axis represents the number of turns on the secondary side of the matching transformer. The number of turns on primary side of the matching transformer is always one. Figure $16 \mathrm{~b}$ shows the relationship between the turn ratio and the proposed inrush current suppressor for the 400-kW SCIM. From these relationships, the capacity of the MC decreases by increasing the turns of the secondary side of the matching transformer. However, the ratio of the regenerated power through the $\mathrm{MC}$ is reduced by increasing the turns. Furthermore, the change in slop of the capacity of the MC decreases gradually from the turn ratio of 1:4. Thus, the appropriate turn ratio is 1:4.
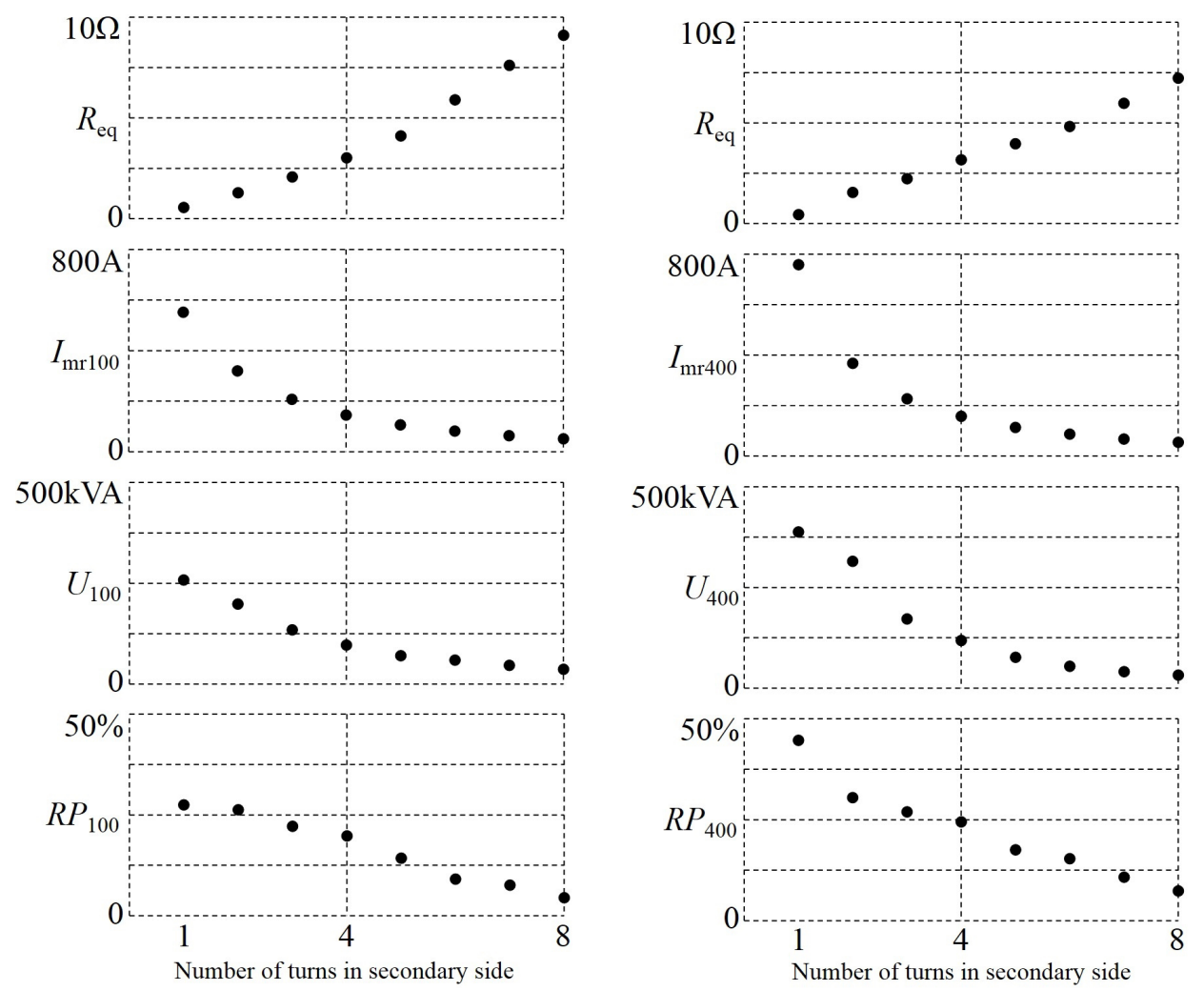

(a)

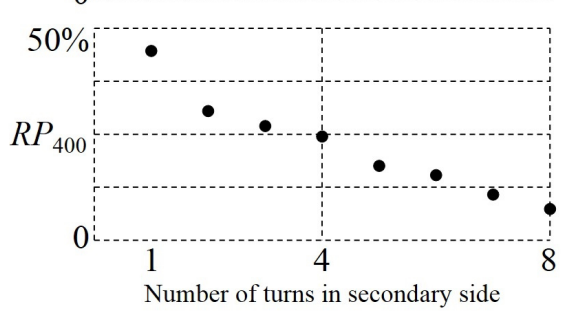

(b)

Figure 16. Relationship between the number of turns on the secondary side of the matching transformer and the proposed inrush current suppressor. (a) For the 100-kW SCIM; (b) For the 400-kW SCIM.

Figure 17 shows the simulation results with the proposed inrush current suppressor for the $100-\mathrm{kW}$ SCIM when the turn ratio is 1:4. $v_{\operatorname{Tr}}$ is the r-phase receiving-end voltage; $i_{\operatorname{Tr}}$ is the r-phase source current; $i_{\mathrm{MTr}}$ is r-phase input current of the MC; $v_{\mathrm{MOr100}}$ is the r-phase output voltage of the $\mathrm{MC} ; i_{\mathrm{mr} 100}$ is the r-phase SCIM current; $S P_{100}$ is the rotating speed; and $v_{\mathrm{w}}$ is the wind speed. From Figure 17, the maximum source current is $146 \mathrm{~A}$. The voltage sag is about $1.01 \%$. The active power that flows into the MC is about $17.1 \mathrm{~kW}$. The receiving-end voltage $v_{\operatorname{Tr}}$ is also opposite in phase to the input current of the MC $i_{\mathrm{MTr}}$. The regenerated-power at the input side of the MC is about $10.6 \mathrm{~kW}$. Figure 18 shows the simulation results with the proposed inrush current suppressor for the $400-\mathrm{kW}$ SCIM when the turn ratio is 1:4. From Figure 18, the maximum source current is $158 \mathrm{~A}$. The voltage sag is about $0.51 \%$. The active power that flows into the MC is about $22.6 \mathrm{~kW}$. The receiving-end voltage $v_{\operatorname{Tr}}$ is also opposite in phase to the input current of the MC $i_{\mathrm{MTr}}$. The regenerated power at the input side of the MC is about $13.4 \mathrm{~kW}$. 
Table 3 shows the comparison between the direct connection, the proposed inrush current suppressor, the soft-starter and the external resistors. The inrush current with the proposed inrush current suppressor is about $10 \%$ as compared to the direct connection. The voltage sag with the proposed inrush current suppressor is about 1.0\%. The THD of the source current with the proposed inrush current suppressor is about $20 \%$, as compared to a soft-starter. The losses of the proposed inrush current suppressor when the turn ratio is $1: 4$ are within $10 \mathrm{~kW}$. Therefore, these results reveal that the proposed inrush current suppressor is useful for practical use.

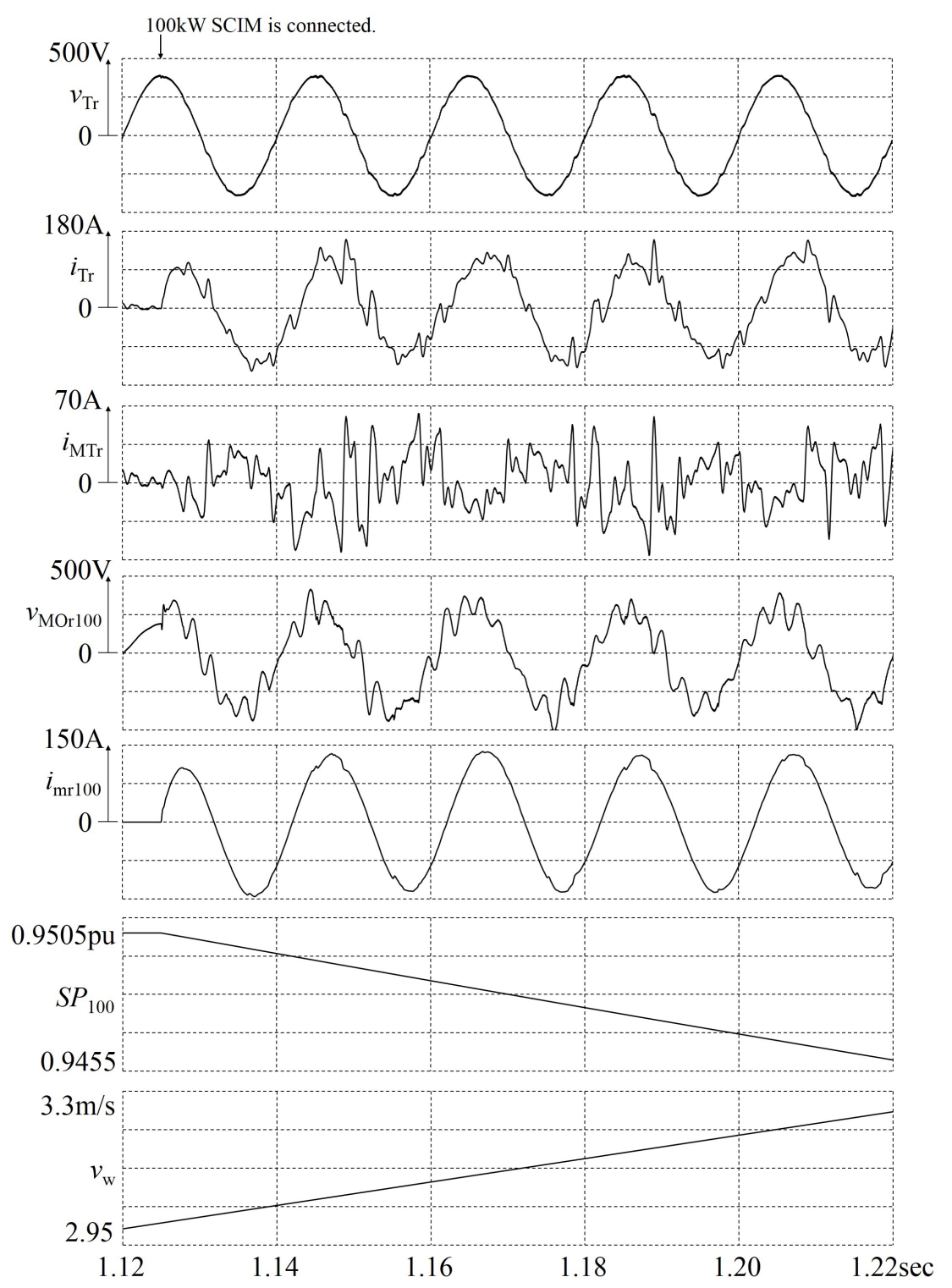

Figure 17. Simulation results with the proposed inrush current suppressor for the 100-kW SCIM when turn ratio is $1: 4$. 


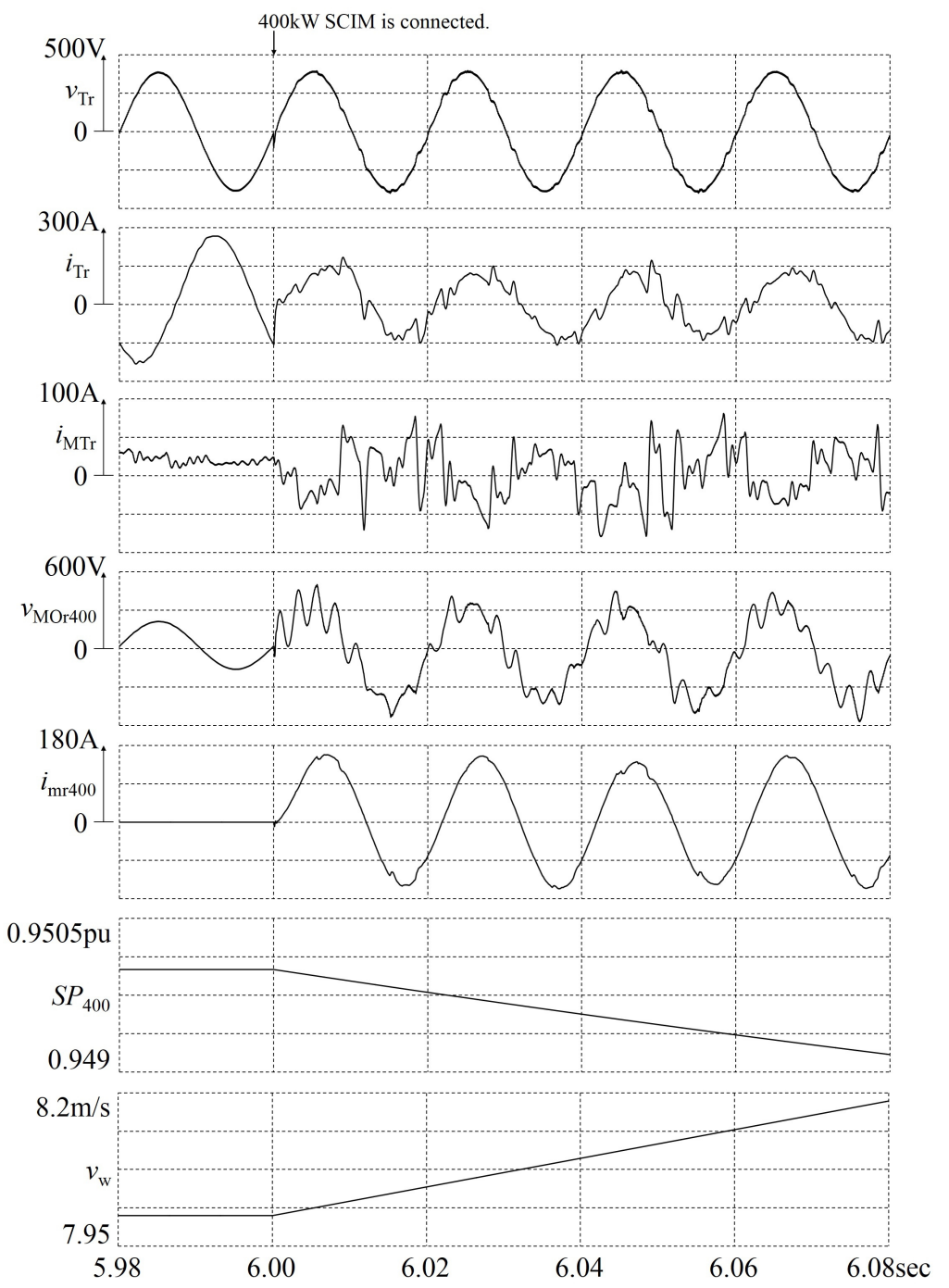

Figure 18. Simulation results with the proposed inrush current suppressor for the 400-kW SCIM when the turn ratio is $1: 4$.

Table 3. Comparison of the simulation results.

\begin{tabular}{|c|c|c|c|c|c|}
\hline \multicolumn{2}{|c|}{ Item } & \multirow{3}{*}{$\begin{array}{c}\begin{array}{c}\text { Inrush } \\
\text { Current (A) }\end{array} \\
1145 \\
3873\end{array}$} & \multirow{3}{*}{$\begin{array}{c}\text { Voltage } \\
\text { Sag (\%) }\end{array}$} & \multirow{3}{*}{$\begin{array}{c}\begin{array}{c}\text { THD of } \\
\text { Source Current (\%) }\end{array} \\
0.08 \\
1.1\end{array}$} & \multirow{3}{*}{$\begin{array}{c}\text { Losses (kW) } \\
- \\
-\end{array}$} \\
\hline & 100-kW SCIM & & & & \\
\hline Direct connection & 400-kW SCIM & & & & \\
\hline \multirow{2}{*}{$\begin{array}{l}\text { Proposed inrush } \\
\text { current suppressor } \\
\text { (turn ratio is } 1: 1 \text { ) }\end{array}$} & 100-kW SCIM & 558 & 1.5 & 7.71 & 14.2 \\
\hline & 400-kW SCIM & 718 & 0.76 & 15.6 & 38.7 \\
\hline \multirow{2}{*}{$\begin{array}{l}\text { Proposed inrush } \\
\text { current suppressor } \\
\text { (turn ratio is } 1: 4 \text { ) }\end{array}$} & 100-kW SCIM & 146 & 1.0 & 20.9 & 6.5 \\
\hline & 400-kW SCIM & 158 & 0.5 & 23.9 & 9.2 \\
\hline \multirow{2}{*}{ Soft-starter } & 100-kW SCIM & 649 & 6.6 & 328.8 & - \\
\hline & 400-kW SCIM & 1941 & 13.8 & 329.96 & - \\
\hline \multirow{2}{*}{ External resistors } & 100-kW SCIM & 512 & 1.0 & - & 119.0 \\
\hline & 400 kW-SCIM & 609 & 0.8 & - & 212.6 \\
\hline
\end{tabular}




\section{Conclusions}

This paper has described the reduced capacity of the inrush current suppressor by using an MC in a large-capacity WPGS with two SCIMs. The inrush current has been confirmed using PSCAD/EMTDC software. The conventional inrush current suppressors, which are the soft-starter and external resistors, were tested in the simulator. From these simulation results, the technical issues have been revealed. The proposed inrush current suppressor has been used in a large-capacity WPGS. From the simulation results, the proposed inrush current suppressor can suppress the inrush current effectively. Furthermore, the appropriate equivalent resistance has been decided for the reduced capacity of the proposed inrush current suppressor by the simulation results. From the simulation results, the capacity of the inrush current suppressor is about $118.7 \mathrm{kVA}$. Thus, the simulation results demonstrated the validity of the proposed inrush current suppressor. Future works are the reduction of the switching ripple and the compensation of the reactive power generated by SCIMs.

Author Contributions: Sho Shibata significantly contributed to the design of the proposed control strategy and contributed to the implementation of the digital computer simulation. Hiroaki Yamada proposed the basic control topology and helped with the writing of this paper. Toshihiko Tanaka and Masayuki Okamoto were responsible for guidance and key suggestions.

Conflicts of Interest: The authors declare no conflict of interest.

\section{References}

1. Global Wind Energy Council. Grobal Wind Energy Outlook 2014. Available online: http://www.gwec. net/wp-content/upload/2015/03/GWEC_Global_Wind_2014_Report_LR.pdf (accessed on 11 November 2015).

2. Thiringer, T.; Petru, T.; Lundberg, S. Flicker contribution from wind turbine installations. IEEE Trans. Energy Convers. 2004, 19, 157-163.

3. Medina-Domínguez, E.J.; Medina-Padrón, J.F. Critical clearing time and wind power in small isolated power systems considering inertia emulation. Energies 2015, 8, 12669-12684.

4. Shinohara, K.; Yamamoto, K.; Iimori, K.; Minari, Y.; Sakata, O.; Miyata, M. Compensating for magnetizing inrush currents in transformers using PWM inverter. IEEJ. Trans. Ind. Appl. 2004, 124, 1173-1181.

5. Yamada, H.; Enami, M.; Hiraki, E.; Tanaka, T. A new method of compensating harmonic currents for wind power generation systems with the soft starter using a hybrid active filter. In Proceedings of the Power Conversion Conference 2007, Nagoya, Japan, 2-5 April 2007; pp. 404-409.

6. Thiringer, T. Grid-friendly connecting of constant-speed wind turbines using external resistors. IEEE Trans. Energy Convers. 2002, 17, 537-542.

7. Yamada, H.; Hanamoto, T. A novel method of suppressing inrush currents of squirrel-cage induction machine using matrix converter in wind power generation systems. In Proceedings of the 2012 International Conference on Renewable Energy Research and Applications (ICRERA), Nagasaki, Japan, 11-14 November 2012; pp. 1-4.

8. Hara, H.; Yamamoto, E.; Yamada, T.; Oyama, J.; Higuchi, T.; Abe, T. Analysis of control performance of matrix converter in a high-speed region using circuit simulator. In Proceedings of the Power Conversion Conference 2007, Nagoya, Japan, 2-5 April 2007; pp. 1072-1077.

9. Ito, J.; Sato, I.; Ohguchi, H.; Sato, K.; Odaka, A.; Eguchi, N. A control method for the matrix converter based on virtual AC/DC/AC conversion using carrier comparison method. IEE Jpn. Ind. Appl. 2004, 124, 457-463.

10. Tadano, Y.; Hamada, S.; Urushibata, S.; Nomura, M.; Sato, Y.; Ishida, M. A space vector modulation scheme for matrix converter that gives top priority to the improvement of the output control performance. IEE Jpn. Ind. Appl. 2008, 128, 631-641.

11. Yoon, Y.D.; Sul, S.K. Carrier-based modulation method for matrix converter with input power factor control and under unbalanced input voltage conditions. In Proceedings of the Twenty Second Annual IEEE Applied Power Electronics Conference, Anaheim, CA, USA, 25 February-1 March 2007; pp. 310-314.

12. Rodriguez, J.; Rivera, M.; Kolar, J.W.; Wheeler, P.W. A review of control and modulation methods for matrix converters. IEEE Trans. Ind. Electron. 2012, 59, 58-70. 
13. Li, Y.; Choi, N.S.; Han, B.M.; Kim, K.M.; Lee, B.; Prak, J.H. Direct duty ratio pulse width modulation method for matrix converters. Int. J. Control Autom. Syst. 2008, 6, 660-669.

14. Yamada, H.; Hanamoto, T. A novel method of suppressing inrush currents of squirrel-cage induction machine using matrix converter in wind power generation systems. In Proceedings of the International Power Electronics Conference (IPEC 2014), Hiroshima, Japan, 18-21 May 2014; pp. 538-542.

15. Alesina, A.; Venturini, M.G.B. Analysis and design of oprimum-amplitude nine-switch direct AC-AC converters. IEEE Trans. Power Electron. 1989, 4, 101-112.

(C) 2016 by the authors; licensee MDPI, Basel, Switzerland. This article is an open access article distributed under the terms and conditions of the Creative Commons by Attribution (CC-BY) license (http:/ / creativecommons.org/licenses/by/4.0/). 